\title{
BMJ Open Age-dependent decline of association between obesity and coronary heart disease: a cohort study in a remote Australian Aboriginal community
}

\author{
Zhiqiang Wang, Wendy E Hoy
}

To cite: Wang Z, Hoy WE. Age-dependent decline of association between obesity and coronary heart disease: a cohort study in a remote Australian Aboriginal community. BMJ Open 2013;3:e004042. doi:10.1136/bmjopen-2013004042

- Prepublication history for this paper is available online. To view these files please visit the journal online (http://dx.doi.org/10.1136/ bmjopen-2013-004042).

Received 16 September 2013 Revised 25 October 2013 Accepted 1 November 2013

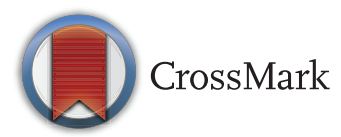

Centre for Chronic Disease, School of Medicine, University of Queensland, Herston, Queensland, Australia

Correspondence to Dr Zhiqiang Wang; z.wang@uq.edu.au

\section{ABSTRACT}

Objective: To determine whether the association between obesity and coronary heart disease (CHD) in Aboriginal adults depends on age.

Design, setting and participants: A cohort study with up to 20 years of follow-up of 849 participants aged $18-76$ years in a remote Aboriginal community in the Northern Territory of Australia.

Main outcome measures: Newly diagnosed CHD cases were identified through hospital records according to ICD codes during the follow-up period. Cox proportional hazard model was used to assess whether the association between obesity and CHD depends on age.

Results: During the follow-up period, 171 participants were diagnosed with CHD. On an average, the incidence rate of $\mathrm{CHD}$ increased with the increasing baseline BMI, $11.3 \%, 16.3 \%$ and $20.2 \%$ for normal weight, overweight and obese groups, respectively. HR of $\mathrm{CHD}$ for obesity were 2.6 (95\% $\mathrm{Cl} 1.1$ to 6.3$), 1.2$ (0.7 to 2.0) and 0.5 (0.1 to 2.1) for those $<40,40-59$ and $60+$ years, respectively. HRs corresponding to 1 SD increase in BMI were 1.4 (1.0 to 2.0), 1.2 (1.0 to $1.5)$ and 0.8 (0.5 to 1.2) for those $<40,40-59$ and 60 + years, respectively. The interaction terms between age and BMI as category variables or as a continuous variable were statistically significant.

Conclusions: The association between obesity and $\mathrm{CHD}$ is stronger for younger adults than for older adults in Aboriginal Australians in the remote community. Our findings suggest that weight control efforts may produce more beneficial effects in CHD prevention in young adults than in older adults.

\section{INTRODUCTION}

It has been well established that overweight and obesity increase the risk of mortality and coronary heart disease (CHD) in a number of studies over several decades. ${ }^{1-8}$ Weight reduction has been found to be beneficial in reducing the CHD risk among overweight and obese people. ${ }^{9-11}$ It has been suggested the effect of body mass index (BMI) on

\section{Strengths and limitations of this study}

- Major strength of the study is the long-term follow-up in a unique high-risk remote Aboriginal community.

- However, since body mass index (BMI) was estimated only once at one age point for each participant, the effect of BMI changes on CHD risk could not be directly assessed.

- Another limitation is that the generalisability of the findings needs to be further verified as this study was conducted in a single Aboriginal community.

cardiovascular disease mortality is modified by age. ${ }^{12}$ A recent analysis by the Emerging Risk Factors Collaboration of a database of over 200000 participants in 51 studies from 17 countries shows that the strength of the association between BMI and CHD was stronger for younger adults than for older adults. $^{13}$ On the other hand, a study on obesity and mortality in the USA suggested that the diminishing obesity-mortality association with age was confounded by age at survey and cohort effects, and once those factors were accounted for, the obesity-mortality became stronger with age. ${ }^{14}$ Understanding the presence of such effect modification by age is important for directing prevention efforts and prioritising public health education. Aboriginal Australians have a high risk of CHD and their CHD is diagnosed at a younger age than non-Aboriginal people. ${ }^{15}$ It is still not known whether obesity has different effects on CHD risk among Aboriginal people of different ages. The objective of this study was to determine whether age modifies the association between BMI and CHD risk. We analysed the cohort data with up to 20 years follow-up from a remote Aboriginal community in the Northern Territory of Australia. 


\section{METHODS}

\section{Participants and CHD events}

This is a prospective cohort study with up to 20 years of follow-up. Participants were recruited from a remote Aboriginal community in the Northern Territory of Australia from 1992 to 1995 . Weight and height were measured for 849 participants aged 18-75 years and who were free from clinically apparent CHD at baseline, representing over $80 \%$ of those within the age range in the region. Those participants were followed up until 31 May 2012. During the follow-up period, new CHD events were identified through hospital records using the International Classification of Diseases codes (ICD 9 codes 410-414, and ICD 10 codes I20-I25), including myocardial infarction (410, I21), angina pectoris (411, I20) and other ischaemic heart disease (413, 414, I22, I23, I24 and I25). Deaths and their causes during the follow-up period were determined through a list of death records maintained at the community clinics. For those participants who reached a CHD event or died from non-CHD causes during the follow-up, their follow-up time was the period from the age of their initial screening visit to the age of the first CHD event or death. Others who survived the follow-period were censored at 31 May 2012. Because individual hospital registration numbers which we used to track study participants were unique throughout the Northern Territory, we were able to capture their hospitalisation records even if our study participants had moved outside the local region. The chance of being hospitalised outside the Northern Territory was extremely low, if any, for people in this remote isolated region. Those without hospital and death records were regarded as free from CHD during the follow-up period.

\section{Baseline BMI measurements}

Height and weight were measured for study participants at baseline during 1992-1995. Height was measured to the nearest $0.5 \mathrm{~cm}$ without shoes. Weight was measured to the nearest $0.1 \mathrm{~kg}$ with participants wearing light clothes only and without shoes. BMI was defined as weight divided by height squared $\left(\mathrm{kg} / \mathrm{m}^{2}\right)$. Since those measurements had been taken several years before the development of CHD, BMI readings were not biased by the presence of CHD endpoints.

\section{Statistical analysis}

The data were partitioned into age bands of $<40,40-59$ and $60+$ years throughout the follow-up. For those whose age fell into two age bands during the follow-up period, their total follow-up time was subdivided and allocated into the corresponding age bands as described by Clayton and Hills. ${ }^{16}$ We calculated the incidence rates of CHD according to their baseline BMI values: $<25$, 2529.9 and $30+\mathrm{kg} / \mathrm{m}^{2}$. HRs of CHD for obesity and $1 \mathrm{SD}$ increase in BMI were calculated with Cox proportional hazards models adjusting for baseline age and gender. We assessed effect-modification with a formal test of the interaction term between age and BMI (or obesity). To further control the effect of competing risk of non-CHD death, we used a competing-risks regression method ${ }^{17}$ to estimate the HRs. All analyses were performed with Stata SE V.12.1. ${ }^{18}$

\section{RESULTS}

Table 1 shows the characteristics of the study participants with different baseline BMI levels. Those obese participants were more likely to be women. They also had higher levels of systolic and diastolic blood pressure, and higher prevalence of known diabetes but lower prevalence of cigarette smoking and alcohol drinking at baseline.

During the follow-up period of 12398 person-years in 849 participants, 128 died from non-CHD causes and 171 were diagnosed with CHD. Table 2 shows the detailed follow-up time and the number of cases by age and BMI groups. On an average, the incidence rates of CHD, which increased with the increasing baseline BMI, were $11.3 \%, 16.3 \%$ and $20.2 \%$ for normal weight, overweight and obese groups, respectively.

Table 1 Baseline characteristics of study participants by baseline BMI levels: mean (SD)

\begin{tabular}{|c|c|c|c|}
\hline & \multicolumn{3}{|l|}{ Baseline BMI $\left(\mathrm{kg} / \mathrm{m}^{2}\right)$} \\
\hline & Normal weight $<25$ & Overweight 25-29.9 & Obese $\geq 30$ \\
\hline Number & 524 & 200 & 125 \\
\hline Male, n (\%) & $285(54.4)$ & $100(50.0)$ & $40(32.0)$ \\
\hline Age, years & $34.2(13.1)$ & $36.0(11.1)$ & $35.5(9.5)$ \\
\hline Weight, kg & $57.0(9.5)$ & $74.8(7.1)$ & $91.1(11.9)$ \\
\hline Height, $\mathrm{cm}$ & $166.3(7.9)$ & $165.9(7.4)$ & $164.8(8.5)$ \\
\hline BMI, $\mathrm{kg} / \mathrm{m}^{2}$ & $20.5(2.6)$ & $27.2(1.3)$ & 33.5 (3.2) \\
\hline Waist c., cm & $81.6(9.5)$ & $97.0(7.2)$ & $110.5(9.4)$ \\
\hline Systolic pressure, $\mathrm{mm} \mathrm{Hg}$ & $119.2(18.5)$ & $125.8(18.0)$ & $126.4(18.9)$ \\
\hline Diastolic pressure, $\mathrm{mm} \mathrm{Hg}$ & $73.0(13.6)$ & 77.7 (12.6) & $79.7(15.7)$ \\
\hline Smoking, $\mathrm{n}(\%)$ & $422(80.5)$ & $137(68.5)$ & $75(60.0)$ \\
\hline Drinking, $\mathrm{n}(\%)$ & $328(62.6)$ & $117(58.5)$ & $53(42.4)$ \\
\hline Known diabetes, $\mathrm{n}(\%)$ & $46(8.8)$ & 25 (12.5) & $23(18.4)$ \\
\hline
\end{tabular}


Table 2 Incidence rate of CHD (per 1000 person-years) by age groups and baseline BMI values

\begin{tabular}{|c|c|c|c|c|c|c|c|c|c|}
\hline \multirow[b]{2}{*}{ Age (years) } & \multicolumn{3}{|l|}{ Normal weight } & \multicolumn{3}{|l|}{ Overweight } & \multicolumn{3}{|l|}{ Obese } \\
\hline & Person-years & Events & Rate & Person-years & Events & Rate & Person-years & Events & Rate \\
\hline$<40$ & 4354 & 16 & 3.7 & 1249 & 8 & 6.4 & 742 & 9 & 12.1 \\
\hline $40-59$ & 2795 & 52 & 18.6 & 1446 & 31 & 21.4 & 925 & 25 & 27.0 \\
\hline $60+$ & 526 & 19 & 36.1 & 247 & 9 & 36.4 & 115 & 2 & 17.3 \\
\hline Total & 7675 & 87 & 11.3 & 2942 & 48 & 16.3 & 1782 & 36 & 20.2 \\
\hline
\end{tabular}

A rising trend in CHD risk with increased BMI was observed in younger age groups (figure 1). Estimated HRs with adjustment of baseline age, gender, known diabetes and smoking status are shown in table 3. For those younger than 40 years, adjusted HRs for overweight and obesity were 1.5 (95\% CI 0.6 to 3.5 ) and 2.6 (95\% CI 1.1 to 6.3 ), respectively, with $\mathrm{BMI}<25 \mathrm{~kg} / \mathrm{m}^{2}$ as the reference group. For those aged 40-59 years, their HRs of CHD were 1.1 (95\% CI 0.7 to 1.8 ) and 1.2 (95\% CI 0.7 to 2.0) for overweight and obesity, respectively. However, for those aged 60 years or older, the CHD risk for normal BMI group was as high as those for overweight and obese groups and no increasing trend in CHD risk with increasing BMI was observed in this age group. To assess whether the association between BMI and CHD risk depended on age and gender, we tested the interaction terms of BMI with age and gender in the Cox proportional hazard models. The overall test for interaction terms between age and BMI categories was statistically significant $(\mathrm{p}=0.012)$.

When BMI was treated as a continuous variable, the HRs corresponding to $1 \mathrm{SD}$ increase in BMI decreased with increasing age, 1.4, 1.2 and 0.8 for those younger

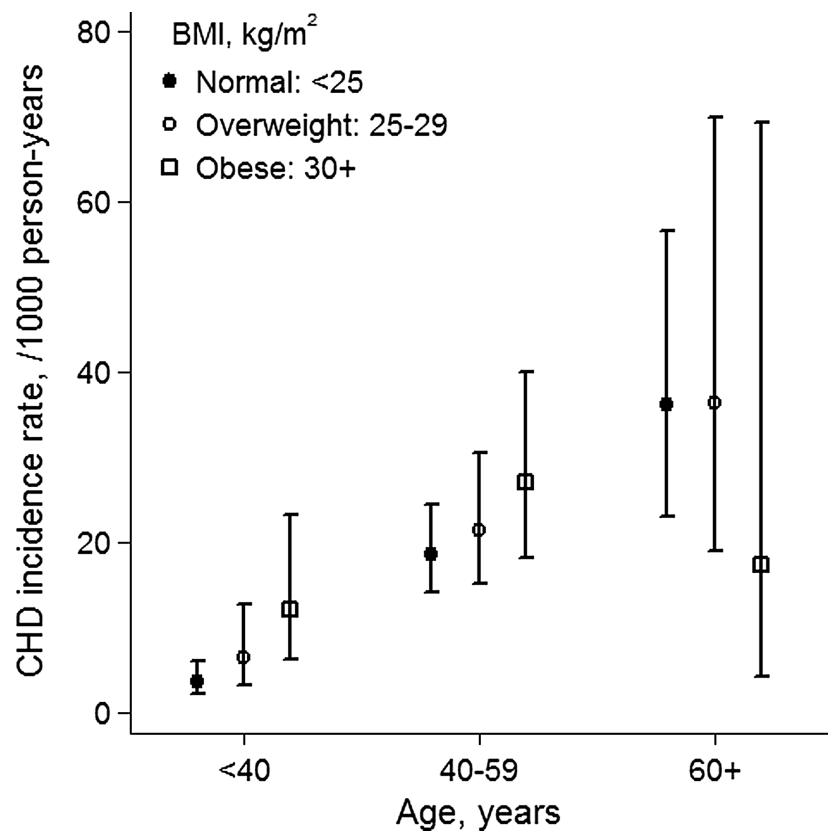

Figure 1 Incidence of coronary heart disease by age and body mass index in Aboriginal adults. than 40, 40-59 and 60 years or older, respectively. The interaction term between age and BMI as a continuous variable was also statistically significant $(\mathrm{p}=0.011)$.

Further adjusting for competing risk of non-CHD deaths, the pattern of the association between CHD and BMI either as a continuous variable or as categorical variables remained similar (table 4 ). The association was stronger for younger adults than for older adults with a statistically significant interaction term between age and BMI.

\section{DISCUSSION}

In this cohort study with up to 20 years follow-up, we found that age is a strong effect-modifier for the association between obesity (or BMI) and CHD in Aboriginal people. The association between obesity and CHD declined with age. The younger they are, the stronger the association between BMI and CHD. Among adults under 40 years, the risk of CHD is 2.6 times in obese individuals as in those with $\mathrm{BMI}<25 \mathrm{~kg} / \mathrm{m}^{2}$, but there is no significant association between obesity and CHD among those 60 years or older. Our findings suggest that the effect of obesity on development of CHD is stronger in younger people than in older people.

It has been well established that the people with high BMI have a high risk of $\mathrm{CHD},{ }^{2-8}$ but a very few studies have assessed the effect modification of the BMI-CHD association by age. The Emerging Risk Factors Collaboration group suggested that age is a strong effect modifier for BMI-CHD association. ${ }^{13}$ They reported that the HRs for CHD associated with per 1 SD increase in BMI decreased with increasing age, from 1.41 for their youngest group (40-59 years) to 1.23 for $60-69$ and 1.12 for 70 years or older. ${ }^{13}$ In our study, we used different age groups because CHD occurred at younger ages in Aboriginal people. ${ }^{15}$ Nevertheless, the pattern of effect modification by age in our study was similar to that reported by the Emerging Risk Factors Collaboration group. To our knowledge, this is the first study to assess effect modification by age in a high-risk indigenous population.

It has also been reported that excess body weight increases the risk of death from any cause and from cardiovascular disease and the relative risk with greater body weight is higher among younger participants in a study of US adults. ${ }^{12}{ }^{19}$ However, a study by Masters et al suggested that survey-based estimates of age patterns in 
Table $3 \mathrm{HRs}^{*}$ of CHD for different baseline BMI levels by age groups

\begin{tabular}{|c|c|c|c|c|c|}
\hline Age (years) & $\begin{array}{l}\text { Overweight† } \\
\text { HR }(95 \% \mathrm{CI})\end{array}$ & $\begin{array}{l}\text { Obese† } \\
\text { HR }(95 \% \mathrm{CI})\end{array}$ & $\begin{array}{l}\text { Interaction } \\
\text { p Value } \neq\end{array}$ & $\begin{array}{l}\text { BMI (1 SD) } \\
\text { HR (95\% CI) }\end{array}$ & $\begin{array}{l}\text { Interaction } \\
\text { p Value }\end{array}$ \\
\hline$<40$ & 1.5 (0.6 to 3.5$)$ & 2.6 (1.1 to 6.3$)$ & 0.012 & 1.4 (1.0 to 2.0$)$ & 0.011 \\
\hline $40-59$ & $1.1(0.7$ to 1.8$)$ & $1.2(0.7$ to 2.0$)$ & & $1.2(1.0$ to 1.5$)$ & \\
\hline $60+$ & 1.0 (0.5 to 2.5$)$ & $0.5(0.1$ to 2.1$)$ & & 0.8 (0.5 to 1.2$)$ & \\
\hline
\end{tabular}

*Adjusted for age, gender, known diabetes and smoking status.

†With BMl $<25 \mathrm{~kg} / \mathrm{m}^{2}$ as reference.

fInteraction between age and $\mathrm{BMI}$ as category variables.

§Interaction between age and $\mathrm{BMI}$ as a continuous variable.

obesity-mortality relationship are confounded by age at survey and cohort membership. When those factors are accounted for, Masters et $a l^{14}$ concluded that the obesity-mortality relationship becomes stronger with age. However, their conclusions might be due to the misinterpretation of main effect coefficients in the presence of interactions. ${ }^{20}$ In this study, controlling for baseline age did not alter in obesity-mortality relationship in different age groups. Those biases caused by cohort membership that Masters $e t$ al proposed were unlikely present because this study was based on the data from a single cohort. Adjusting for the competing risk of non-CHD death and the potential confounding effects of smoking, diabetes and gender did not alter the age pattern of the BMI-CHD relationship.

It is not clear why the effect of obesity (or higher BMI) on development of CHD declines as people get older. A similar pattern of the age-dependent significant attenuation between obesity and CHD risk factors such as hyperglycaemia, hypertension and dyslipidaemia could partly explain the observed age-dependent decline between obesity and development of CHD. ${ }^{21}{ }^{22}$ This phenomenon, if further confirmed in interventional studies, may have clinical and public health implications of weight control in people of different ages. Our findings stress the importance of weight reduction targeting younger adults for reducing CHD risk in this population. The same amount of weight reduction in younger people may produce more beneficial effects on CHD risk reduction than in their older counterparts. Several other factors have been found to be associated with CHD or cardiovascular disease risk in this population such as $\mathrm{C}$ reactive protein ${ }^{23}$ and albuminuria ${ }^{24}$ in addition to conventional risk factors. ${ }^{25}{ }^{26}$ Since obesity has been considered to affect CHD risk through its influence on those known risk factors, ${ }^{27}$ we did not adjust for those known risk factors in our analysis.

There are several limitations in this study. BMI was estimated only once at one age point for each participant and no recent BMI values were taken. Therefore, the effect of BMI changes on CHD risk could not be directly assessed. The CHD cases were identified through routinely documented hospital records during the follow-up period. Under-reporting is possible as some participants with minor CHD events may not be hospitalised and diagnosed as such. However, there is no evidence that such under-reporting could have occurred differently among people with different BMI levels. Another limitation of this study is the small sample size, particularly for the older age group. Although the interaction term for testing the dependence of the BMI-CHD association on age was statistically significant, the association between BMI and CHD in the older age group could not be accurately estimated as reflected by the wide $95 \%$ CIs. Finally, the study was conducted in a single relatively homogenous population in one community. It remains to be verified whether our findings can be applied to the general Aboriginal population in Australia.

\section{CONCLUSION}

The association between obesity and CHD declines with increasing age and is stronger in young adults than for older adults in Aboriginal Australians. Our findings imply that the efforts of obesity prevention and weight control are more likely to produce beneficial effects on CHD prevention in younger than in older people. Further interventional studies are needed to quantify

Table 4 HRs of CHD for different baseline BMI levels adjusting for competing risk of non-CHD death

\begin{tabular}{|c|c|c|c|c|c|}
\hline Age (years) & $\begin{array}{l}\text { Overweight* }^{*} \\
\text { HR }(95 \% \mathrm{CI})\end{array}$ & $\begin{array}{l}\text { Obese }^{\star} \\
\text { HR }(95 \% \mathrm{CI})\end{array}$ & $\begin{array}{l}\text { Interaction } \\
\text { p Valuet }\end{array}$ & $\begin{array}{l}\text { BMI (1 SD)* } \\
\text { HR }(95 \% \mathrm{Cl})\end{array}$ & $\begin{array}{l}\text { Interaction } \\
\text { p Value }\end{array}$ \\
\hline$<40$ & 1.5 (0.6 to 3.6$)$ & 2.6 (1.1 to 6.0$)$ & 0.026 & 1.4 (1.1 to 2.0$)$ & 0.012 \\
\hline $40-59$ & $1.2(0.7$ to 1.8$)$ & $1.3(0.8$ to 2.1$)$ & & $1.2(1.0$ to 1.4$)$ & \\
\hline $60+$ & $1.2(0.6$ to 2.5$)$ & $0.5(0.1$ to 2.1$)$ & & 0.8 (0.5 to 1.2$)$ & \\
\hline
\end{tabular}

${ }^{*}$ Adjusted for competing risk of non-CHD death, age, gender, known diabetes and smoking status. 
the effect of weight reduction on CHD risk in people of different ages.

Acknowledgements The authors especially thank the Aboriginal people who participated in this study. Shuqin Li at the Northern Territory Department of Health assisted in the interpretation of hospital data.

Contributors WEH and ZW conceived the idea of the study and were responsible for the design of the study. WEH provided input into the data analysis and was responsible for the acquisition of the baseline data. ZW was responsible for linking baseline and hospital data and for undertaking data analysis. Both WEH and ZW contributed to the first draft, and read and approved the final version.

Funding This work was supported by NHMRC of Australia (APP1025300/ 1025350).

Competing interests WEH was supported by Australian Fellowship (\#511081) and ZW by NHMRC Fellowship (APP1042343).

Ethics approval The project was approved by the University of Queensland Behavioural and Social Science Ethical Review Committee (\#2011001232).

Provenance and peer review Not commissioned; externally peer reviewed.

Open Access This is an Open Access article distributed in accordance with the Creative Commons Attribution Non Commercial (CC BY-NC 3.0) license, which permits others to distribute, remix, adapt, build upon this work noncommercially, and license their derivative works on different terms, provided the original work is properly cited and the use is non-commercial. See: http:// creativecommons.org/licenses/by-nc/3.0/

\section{REFERENCES}

1. Flegal KM, Kit BK, Orpana $\mathrm{H}$, et al. Association of all-cause mortality with overweight and obesity using standard body mass index categories: a systematic review and meta-analysis. JAMA 2013:309:71-82.

2. Harris TB, Launer LJ, Madans J, et al. Cohort study of effect of being overweight and change in weight on risk of coronary heart disease in old age. BMJ 1997;314:1791-4.

3. Manson JE, Colditz GA, Stampfer MJ, et al. A prospective study of obesity and risk of coronary heart disease in women. $N$ Engl J Med 1990;322:882-9.

4. Keys A, Aravanis $\mathrm{C}$, Blackburn $\mathrm{H}$, et al. Coronary heart disease: overweight and obesity as risk factors. Ann Intern Med 1972;77:15-27.

5. Logue J, Murray HM, Welsh $\mathrm{P}$, et al. Obesity is associated with fatal coronary heart disease independently of traditional risk factors and deprivation. Heart 2011;97:564-8.

6. Nguyen NT, Nguyen XM, Wooldridge JB, et al. Association of obesity with risk of coronary heart disease: findings from the National Health and Nutrition Examination Survey, 1999-2006. Surg Obes Relat Dis 2010;6:465-9.

7. Nanchahal K, Morris JN, Sullivan LM, et al. Coronary heart disease risk in men and the epidemic of overweight and obesity. Int $J$ Obes (Lond) 2005;29:317-23.

8. Stevens J, Erber E, Truesdale KP, et al. Long- and short-term weight change and incident coronary heart disease and ischemic stroke: the Atherosclerosis Risk in Communities Study. Am J Epidemiol 2013;178:239-248.

9. Sartorio A, Lafortuna CL, Marinone PG, et al. Short-term effects of two integrated, non-pharmacological body weight reduction programs on coronary heart disease risk factors in young obese patients. Diabetes Nutr Metab 2003;16:262-5.

10. Vogel JA, Franklin BA, Zalesin KC, et al. Reduction in predicted coronary heart disease risk after substantial weight reduction after bariatric surgery. Am J Cardiol 2007;99:222-6.

11. Eilat-Adar S, Eldar M, Goldbourt U. Association of intentional changes in body weight with coronary heart disease event rates in overweight subjects who have an additional coronary risk factor. $\mathrm{Am}$ $J$ Epidemiol 2005;161:352-8.

12. Stevens J, Cai J, Pamuk ER, et al. The effect of age on the association between body-mass index and mortality. $N$ Engl J Med 1998;338:1-7.

13. The Emerging Risk Factors Collaboration. Separate and combined associations of body-mass index and abdominal adiposity with cardiovascular disease: collaborative analysis of 58 prospective studies. Lancet 2011;377:1085-95.

14. Masters RK, Powers DA, Link BG. Obesity and US mortality risk over the adult life course. Am J Epidemiol 2013;177:431-42.

15. Wang Z, Hoy WE. Lifetime risk of developing coronary heart disease in Aboriginal Australians: a cohort study. BMJ Open 2013;3: e002308.

16. Clayton D, Hills M. Statistical models in epidemiology. Oxford: Oxford University Press, 1993.

17. Fine JP, Gray RJ. A proportional hazards model for the subdistribution of a competing risk. J Am Stat Assoc 1999;94:496-509.

18. Stata Statistical Software: Release 12 [program]. College Station, TX: StataCorp LP, 2011.

19. Singh PN, Lindsted KD. Body mass and 26-year risk of mortality from specific diseases among women who never smoked. Epidemiology 1998;9:246-54.

20. Wang Z. Obesity and US mortality risk over adult life course: misinterpretation of main effect estimates in the presence of interactions. Am J Epidemiol 2013;in press.

21. Wakabayashi I. Age-dependent influence of gender on the association between obesity and a cluster of cardiometabolic risk factors. Gen Med 2012;9:267-77.

22. Wakabayashi I, Daimon T. Age-dependent decline of association between obesity and hyperglycemia in men and women. Diabetes Care 2012:35:175-7.

23. Wang Z, Hoy WE. C-reactive protein: an independent predictor of cardiovascular disease in Aboriginal Australians. Aust N Z J Public Health 2010;34(Suppl 1):S25-9.

24. Wang Z, Hoy WE. Albuminuria and incident coronary heart disease in Australian Aboriginal people. Kidney Int 2005;68:1289-93.

25. Wang Z, Hoy WE. Association between diabetes and coronary heart disease in Aboriginal people: are women disadvantaged? Med $J$ Aust 2004;180:508-11.

26. Wang Z, Hoy WE. Is the Framingham coronary heart disease absolute risk function applicable to Aboriginal people? Med J Aust 2005;182:66-9.

27. Poirier P, Giles TD, Bray GA, et al. Obesity and cardiovascular disease: pathophysiology, evaluation, and effect of weight loss: an update of the 1997 American Heart Association Scientific Statement on Obesity and Heart Disease from the Obesity Committee of the Council on Nutrition, Physical Activity, and Metabolism. Circulation 2006;113:898-918. 